\title{
THEORETICAL INVESTIGATIONS ON DETONATION PERFORMANCE AND STABILITY OF THE DIFLUOROAMINO-PRISMANE DERIVATIVES
}

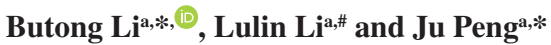

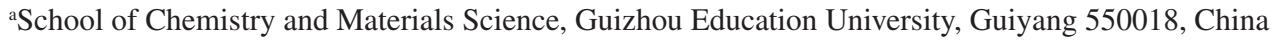

Recebido em 01/08/2020; aceito em 20/10/2020; publicado na web em 18/11/2020

\begin{abstract}
The difluoroamino derivatives of prismane were designed and calculated at the B3LYP/6-311G** level. The detonation performances, as well as the band gap, were investigated to look for high energy density compounds. Our calculations showed that difluoroamino group is an effective substitute group for increasing density and heats of formation. All compounds have large heats of formation, and there is a linear relationship between the heats of formation (HOFs) and the substituent numbers. Bond dissociation energies of trigger bonds are all over $200 \mathrm{~kJ} / \mathrm{mol}$, which indicated that these prismane derivatives have good stability. More than three substituted groups made the detonation performances meet the requirement of energetic materials. Our calculations provided basic information for the further syntheses of title molecules.
\end{abstract}

Keywords: high energy density compounds; Kamlet-Jacobs equation; density function theory; prismane derivatives.

\section{INTRODUCTION}

In the past decades, the research of energetic materials through theoretical methods has greatly accelerated the development of such materials and provided a profound understanding. ${ }^{1-6}$ The use of theoretical methods to predict the detonation performance and stability of energetic compounds has many benefits, such as reducing the cost of experimental synthesis and detection, increasing the efficiency of the cost, being environmentally friendly, saving time. Generally, good detonation properties and the bluntness of molecules are the two most important aspects of energetic compounds, which are often contradictory and difficult to obtain at the same time..$^{7,8}$ Therefore, how to obtain a material with both good detonation performance and sufficient stability is our research goal. In practice, new energetic compounds are often designed by modifying high nitrogen-content or high strain structure by addition and/or modification of energetic groups. ${ }^{9,10}$

The nitro compound itself has a sufficiently large molecular density and generating heat, which makes it a traditional excellent energetic material and widely used. ${ }^{11-14}$ Among various types of the high energy density compounds (HEDCs), organic cage compounds especially have attracted much attention. The most famous of these molecules is hexanitrohexaazaisowurtzitane (CL-20) ${ }^{15,16}$ and octanitrocubane (ONC), ${ }^{17-19}$ their synthesis as a breakthrough in the history of explosive development. Prismane $\left(\mathrm{C}_{6} \mathrm{H}_{6}\right)$ is another important organic cage compound, which has been synthesized and fully characterized. ${ }^{20}$ Its characteristics include the high symmetry $\left(D_{3 \mathrm{~h}}\right)$, large ring strain energy $\left(609.9 \mathrm{~kJ} \mathrm{~mol}^{-1}\right)$, and so on. ${ }^{21}$ At present, some prismane derivatives have been studied as HEDCs, such as polyisocyanopriamanes, ${ }^{22}$ polyazidoprismane, ${ }^{23}$ and polynitropriamanes. To our knowledge, difluoroamino $\left(\mathrm{NF}_{2}\right)$ derivatives of prisms have not been reported in the literature. And the $\mathrm{NF}_{2}$ group has been proved to be an excellent energetic group by previous work, ${ }^{24-26}$ and its access can effectively improve the density and detonation performance of the molecule. In our work, we suggested that the $\mathrm{H}$ atoms in prismane skeleton were replaced with the difluoroamino group to get difluoroaminoprismane derivatives.

*e-mail: butong.lee@gmail.com

\#alternative e-mail: lulin.li@outlook.com
The heats of formation, electronic structure, density, energetic performances, and the thermal stability were investigated.

\section{CALCULATION METHOD}

The difluoroaminoprismane derivatives were fully optimized at the B3LYP/6-311G** level ${ }^{27}$ using the Gaussian 03 program package $^{28}$ and shown in Figure 1.

The isodesmic reactions ${ }^{29-32}$ were designed to obtain heats of formation (HOFs), and the formula is followed:

$$
\mathrm{C}_{6} \mathrm{H}_{6-n}\left(\mathrm{NF}_{2}\right)_{n}+n \mathrm{CH}_{4}=\mathrm{C}_{6} \mathrm{H}_{6}+n \mathrm{CH}_{3} \mathrm{NF}_{2}(\mathrm{n}=1-6)
$$

The HOF was calculated according to the reaction enthalpy of the isodesmic reaction, and the equation is as followed:

$$
H_{\mathrm{f}, \mathrm{p}}-\Delta H_{\mathrm{f}, \mathrm{r}}
$$

where $\Delta H_{\mathrm{f}, \mathrm{p}}$, and $\Delta H_{\mathrm{f}, \mathrm{r}}$ are the HOFs of the products and reactants at $298 \mathrm{~K}$ respectively. The experimental HOFs of reference compounds $\mathrm{CH}_{4}$ and $\mathrm{C}_{6} \mathrm{H}_{6}$ are taken from the NIST Chemistry WebBook. Thus, the HOFs of the difluoroaminoprismane derivatives can be calculated when the heat of reaction $\Delta H_{298}$ is known. The $\Delta H_{298}$ can be calculated using the following equation:

$$
\Delta H_{298}=\Delta E+\Delta \mathrm{ZPE}+H_{\mathrm{T}}+\Delta n R T
$$

where $\Delta E$ is the change in total energy between the products and reactants at $0 \mathrm{~K} . \triangle \mathrm{ZPE}$ is the difference between the zero-point energy of products and reactants. The $\Delta H_{\mathrm{T}}$ is the thermal correction from 0 to $298 \mathrm{~K} . \Delta n R T$ is the work term, which equals zero here.

To measure the strength of the trigger bonds, the bond dissociation energies (BDE) were calculated. ${ }^{33,34} \mathrm{BDE}$ is the energy required for the homolytic cleavage of a bond and is commonly denoted as the difference between the total energies of the radical products and the reactants. The $\mathrm{BDE}$ values of $\mathrm{C}-\mathrm{NF}_{2}$ bonds were calculated as follows:

$$
\mathrm{BDE}_{(\mathrm{A}-\mathrm{B})}=\mathrm{E}_{(\mathrm{A} \bullet)}+\mathrm{E}_{(\mathrm{B} \bullet)}-\mathrm{E}_{(\mathrm{A}-\mathrm{B})}
$$

Considering the open-shell nature of the radical, unrestricted 


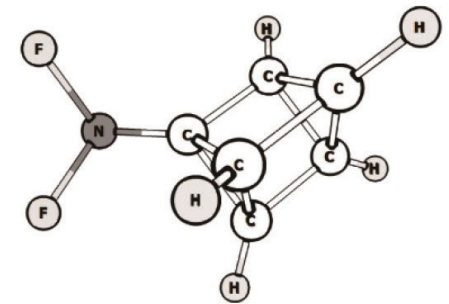

$1-$

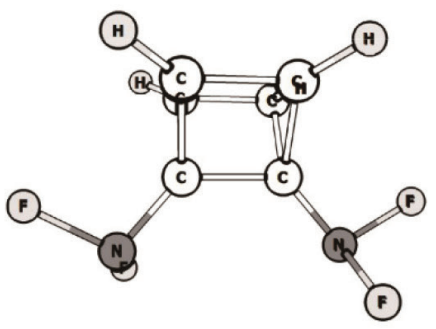

$1,5-$

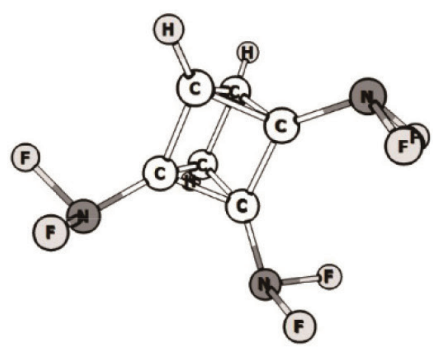

$1,2,6-$

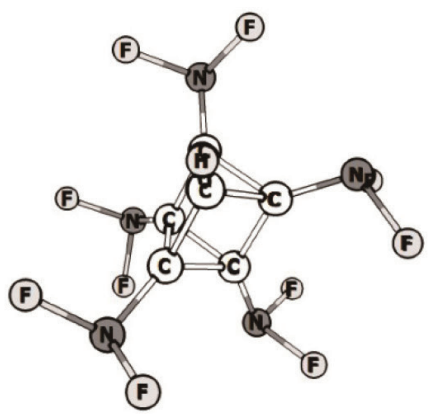

$1,2,3,4,5-$

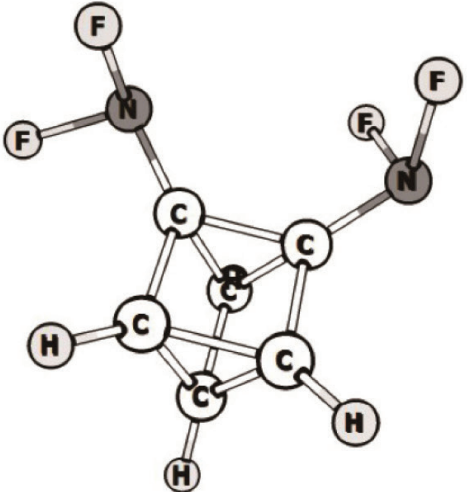

$1,2-$

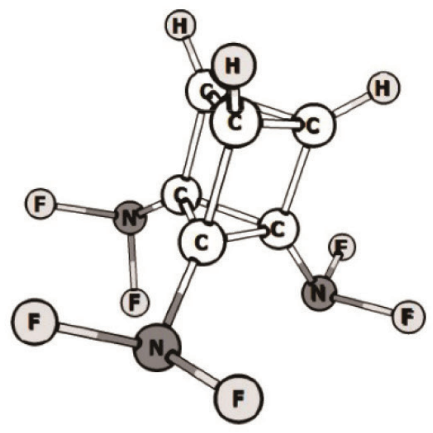

$1,2,3-$

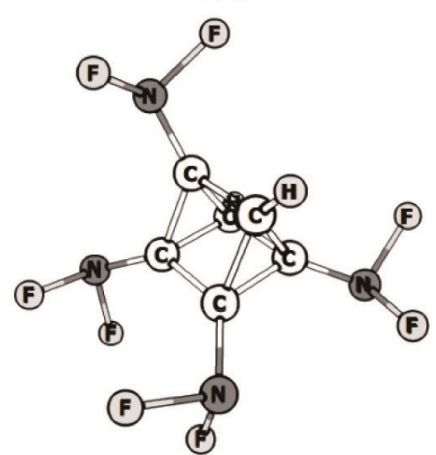

$1,2,4,5-$

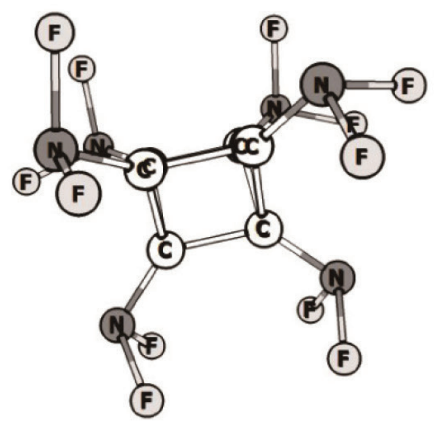

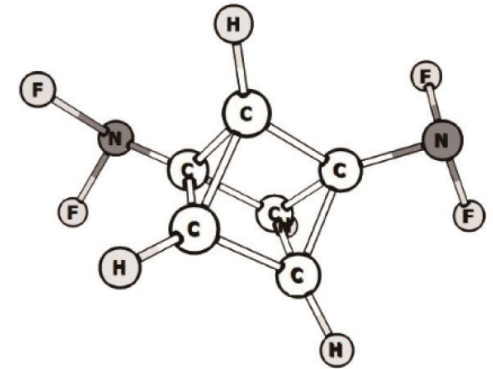

$1,4-$

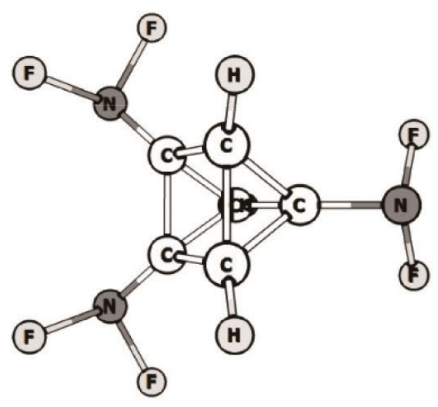

$1,2,4-$<smiles>O=C1OC2(OC(=O)C(O)(O)C2=O)C1=O</smiles>

$1,2,3,4-$

Figure 1. Structures of title molecules optimized at the B3LYP/6-311G** level

hybrid functional DFT-UB3LYP was used. The BDE with zero-point energy (ZPE) correction can be calculated via equation (5).

$$
\mathrm{BDE}(\mathrm{A}-\mathrm{B})_{\mathrm{ZPE}}=\mathrm{BDE}_{(\mathrm{A}-\mathrm{B})}+\Delta \mathrm{ZPE}
$$

where $\triangle \mathrm{ZPE}$ is the difference between the ZPEs of the products and the reactants.

Detonation velocity $(D)$, and detonation pressure $(P)$ are used to evaluate the explosive performances of energetic materials by using the empirical Kamlet-Jacobs equations: ${ }^{35-37}$

$$
\begin{gathered}
D=1.01\left(N \bar{M}^{1 / 2} Q^{1 / 2}\right)^{1 / 2}(1+1.30 \rho) \\
P=1.588 \rho^{2} N \bar{M}^{1 / 2} Q^{1 / 2}
\end{gathered}
$$

where $D$ is the detonation velocity $(\mathrm{km} / \mathrm{s}) ; P$ is the detonation pressure (GPa); $N$ is the moles of gas produced per gram of explosive and $\bar{M}$ is 
the mean molecular weight of the gaseous detonation products; $Q$ is the detonation energy $(\mathrm{cal} / \mathrm{g}) ; \rho$ is molecular theory density $\left(\mathrm{g} \mathrm{cm}^{-3}\right)$, which was calculated from the molar weight $(M)$ divided by the average value molar volume $(V)$, which was defined as the volume of 0.001 electrons $/$ bohr $^{3}$ electron density envelope.

The combustion reaction is designed as:

$4 \mathrm{C}_{6} \mathrm{H}_{6}-n\left(\mathrm{NF}_{2}\right)_{n}+(30-3 n) \mathrm{O}_{2} \rightarrow(12-2 n) \mathrm{H}_{2} \mathrm{O}+(24-2 n) \mathrm{CO}_{2}+$ $2 n \mathrm{CF}_{4}+2 n \mathrm{~F}_{2}$

The specific combustion enthalpy $\left(\Delta H_{\text {comb }}\right)$ can be calculated from the heats of formation of the explosive compound and the gaseous products as follows:

$$
\Delta H_{\text {comb }}=\frac{1}{4 M}\left(\sum_{\text {products }} N_{\mathrm{i}} \Delta H_{f, i}-N_{H E D C} \Delta H_{f, H E D C}\right)
$$

in which $H_{f, i}$ and $\Delta H_{f, H E B C}$ is the heat of formation of the products and reactant, respectively. $N$ is the stoichiometric number. $M$ is the molecular weight. $H_{\text {comb }}$ is the combustion enthalpy.

\section{RESULTS AND DISCUSSION}

\section{Heats of formation and molecular stabilities}

HOF reflects the energy content of a compound. High positive HOF is usually required for an effective energetic compound. Therefore, the HOFs are obtained by using the isodesmic reactions, and listed in Table 1.

As is evident in Table 1, HOFs of all difluoroaminoprismane derivatives are large and positive, which indicates energetic nature. It is noteworthy that HOFs decrease as the increasing of the substituent group numbers when $n \leq 4$. However, when $n>4$, the HOFs values become large with the substitute group increased. Also, there is a good polynomial relationship between HOFs and the numbers of substitute groups (Figure 2): $\mathrm{HOF}=5.8384 x^{2}-49.821 x+555.54\left(\mathrm{R}^{2}=0.8693\right)$. It should be noted that the average values of HOFs of isomers were used to discuss. Then, the contributions of difluoroamino group on the HOFs of difluoroamino prismane derivatives can not meet the group additivity principle. For the isomers, HOFs values are different from each other, which presents that the HOFs are affected by the position of the difluoroamino group. Generally speaking, the closer difluoroamino group results in higher HOFs and less thermodynamic stability. For instance, the 1,2-didifluoroaminoprismane has two difluoroamino groups located the same three-membered rings and has the higher HOFs than the other two difluoroamino substituted derivatives; 1,5-didifluoroaminoprismane has the largest distance of two difluoroamino groups in all di-substituted derivatives, so it has the least HOF.

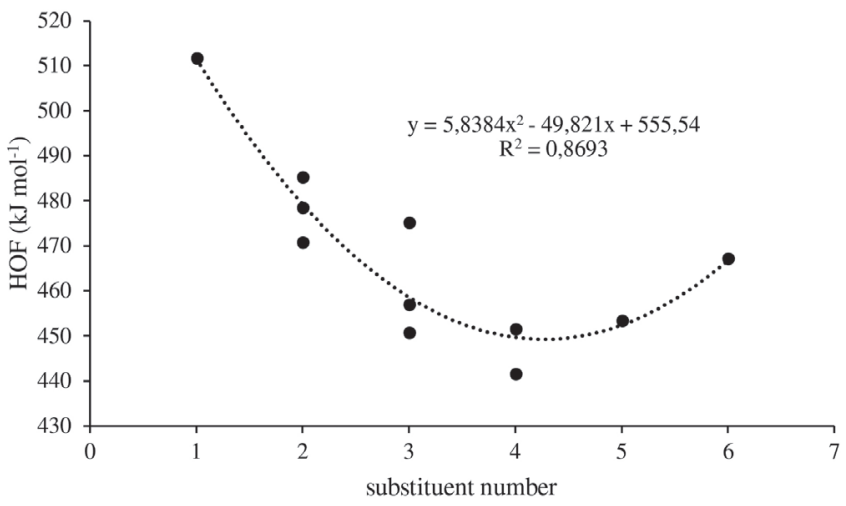

Figure 2. Corelation between the substituent number and the heat of formation of title molecules

The combustion enthalpy is also an important parameter for high energy density compound to predict the energy content. Therefore, the combustion reaction is designed and the combustion enthalpy is calculated by using the equation (8). The final results are listed in the last column of Table 1. Based on our calculations, the specific combustion enthalpy is reduced with the introduction of the difluoroamino groups. The correlation was performed and plotted in Figure 3. The correlation equation is $\Delta H_{\text {comb }}=-0.6259 \mathrm{x}^{2}+7.3042 \mathrm{x}-$ $32.888\left(R^{2}=0.9913\right)$. Overall, the tendency is consistent between the combustion enthalpy and the heat of formation.

\section{Electronic structure}

Band gap $\left(E_{\mathrm{g}}\right)$ is defined as the energy gap between the highest occupied molecular orbital (HOMO) and the lowest unoccupied molecular orbital (LUMO) and represents the dynamic stability of energetic materials. ${ }^{38}$ Then, $E_{\mathrm{g}}$ were calculated at the B3LYP/6-311G** level and listed in Table 2.

Table 1. Calculated total energies ( $E$, a.u.), thermal corrections $\left(H_{\mathrm{T}}\right.$, a.u.), zero-point energies (ZPE, a.u.), heats of formation (HOF, kJ mol $\left.{ }^{-1}\right)$, and specific combustion enthalpy $\left(H_{\text {comb }}, \mathrm{kJ} \mathrm{g}^{-1}\right)$ at the B3LYP/6-311G** Level

\begin{tabular}{|c|c|c|c|c|c|}
\hline Compound & $E_{0}$ & $\mathrm{ZPE}$ & $H_{\mathrm{T}}$ & $\mathrm{HOF}$ & $H_{\text {comb }}$ \\
\hline $1-$ & -485.88090 & 0.09589 & 0.00698 & 511.75 & -26.96 \\
\hline $1,2-$ & -739.64130 & 0.09500 & 0.01092 & 485.31 & -20.38 \\
\hline $1,4-$ & -739.64380 & 0.09490 & 0.01097 & 478.62 & -20.35 \\
\hline $1,5-$ & -739.64680 & 0.09498 & 0.01093 & 470.84 & -20.31 \\
\hline $1,2,3-$ & -993.39447 & 0.09404 & 0.01396 & 475.31 & -16.61 \\
\hline $1,2,4-$ & -993.40141 & 0.09399 & 0.01401 & 457.09 & -16.54 \\
\hline $1,2,6-$ & -993.40378 & 0.09395 & 0.01403 & 450.81 & -16.51 \\
\hline $1,2,3,4-$ & -1247.15665 & 0.09290 & 0.01717 & 441.62 & -14.06 \\
\hline $1,2,4,5-$ & -1247.15272 & 0.09276 & 0.01720 & 451.65 & -14.09 \\
\hline $1,2,3,4,5-$ & -1500.90134 & 0.09167 & 0.02032 & 453.46 & -12.39 \\
\hline $1,2,3,4,5,6-$ & -1754.64542 & 0.09054 & 0.02350 & 467.24 & -11.15 \\
\hline $\mathrm{C}_{6} \mathrm{H}_{6}$ & -232.014465 & 0.096673 & 0.10171 & 597.1 & -48.9 \\
\hline
\end{tabular}




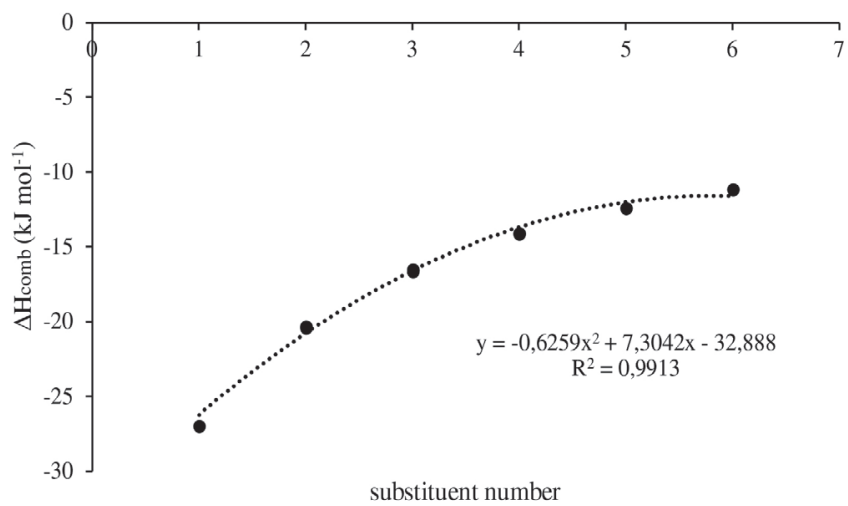

Figure 3. Correlation bewteen the substituent number and the specific combustion enthalpy

Table 2. Calculated HOMO and LUMO energies (a.u.), band gap $\left(E_{\mathrm{g}}\right)$ of the title compounds at the B3LYP/6-311G** level

\begin{tabular}{lccc}
\hline Compounds & $E_{\text {LUмо }}$ & $E_{\text {номо }}$ & $E_{\mathrm{g}}$ \\
\hline $1-$ & 0.00307 & -0.25380 & 0.25687 \\
$1,2-$ & -0.02588 & -0.27301 & 0.24713 \\
$1,4-$ & -0.01916 & -0.27528 & 0.25612 \\
$1,5-$ & -0.02032 & -0.27751 & 0.25719 \\
$1,2,3-$ & -0.05039 & -0.29317 & 0.24278 \\
$1,2,4-$ & -0.04314 & -0.29394 & 0.25080 \\
$1,2,6-$ & -0.04221 & -0.29060 & 0.24839 \\
$1,2,3,4-$ & -0.06408 & -0.30738 & 0.24330 \\
$1,2,4,5-$ & -0.06182 & -0.30865 & 0.24683 \\
$1,2,3,4,5-$ & -0.08167 & -0.31823 & 0.23656 \\
$1,2,3,4,5,6-$ & -0.09793 & -0.33034 & 0.23241 \\
$\mathrm{C}_{6} \mathrm{H}_{6}$ & 0.05360 & -0.23150 & 0.28510 \\
$\mathrm{TATB}_{\mathrm{ATB}}$ & -0.10280 & -0.26480 & 0.16210 \\
\hline
\end{tabular}

It is interesting to note that all prismane derivatives have reduced $E_{\mathrm{g}}$ compared to that of the prismane parent body. Besides, the $E_{\mathrm{g}}$ has a good linear relationship with the numbers of difluoroamino group: $E_{\mathrm{g}}=-0.005 n+0.2629\left(R^{2}=0.9898\right)$. High band gaps indicate high stability and small gap implies low stability. To our surprise, the band gaps of prismane derivatives are much higher than 0.1630 a.u. of 1,3,5-triamino-2,4,6-trinitrobenzene (TATB), which means title molecules are more insensitive than TATB.

\section{Bond dissociation energies}

Several simple relationships have been found that relate stability with direct and indirect molecular properties such as the oxygen balance of the compound, ${ }^{39}$ molecular electronegativities ${ }^{40}$ vibrational states ${ }^{41}$ and so on. However, the bond dissociation energies of trigger bonds are more clear and effective in investigating the stability and pyrolysis mechanism of HEDCs. For time-saving, the BDEs were obtained for the trigger bond, which is the initiate bond in detonation reaction and characterized by the weakest bond order of a molecule. Then, the bond orders and bond dissociation energies are calculated and listed in Table 3.

From Table 3, it can be found that the $\mathrm{BDE}_{\mathrm{C}-\mathrm{CF} 2}^{0}$, value is lowered by ca. $20 \mathrm{~kJ} \mathrm{~mol}^{-1}$ after the zero-point correction compared to $\mathrm{BDE}_{\mathrm{C}-\mathrm{NF2}}$. Because the isomers with the same substituent group have different $\mathrm{BDE}$ values, the BDE is affected by the position of
Table 3. Calculated bond dissociation energies $(\mathrm{kJ} / \mathrm{mol})$ for the possible rupture of the weakest $\mathrm{C}-\mathrm{NF}_{2}$ bond at the UB3LYP/6-311G** levels

\begin{tabular}{lccc}
\hline Compounds & Bond Order & $B D E_{\mathrm{C}-\mathrm{NF} 2}$ & $B D E_{\mathrm{C}-\mathrm{NF} 2}^{0}$ \\
\hline $1-$ & 1.0208 & 285.52 & 269.05 \\
$1,2-$ & 1.0191 & 271.56 & 255.55 \\
$1,4-$ & 1.0193 & 277.28 & 261.44 \\
$1,5-$ & 1.0152 & 277.94 & 261.83 \\
$1,2,3-$ & 1.0296 & 260.87 & 244.82 \\
$1,2,4-$ & 1.0152 & 272.11 & 256.21 \\
$1,2,6-$ & 1.0118 & 272.24 & 256.30 \\
$1,2,3,4-$ & 1.0140 & 268.48 & 252.91 \\
$1,2,4,5-$ & 1.0174 & 260.55 & 245.16 \\
$1,2,3,4,5-$ & 1.0151 & 257.77 & 242.28 \\
$1,2,3,4,5,6-$ & 1.0275 & 249.29 & 233.58 \\
\hline
\end{tabular}

the substituent groups. Looking inside the data, the closer substituent groups result in smaller BDE and lower thermodynamic stability. All derivatives of prismane have large BDE values over $200 \mathrm{~kJ} \mathrm{~mol}^{-1}$, meeting the basic requirement of high-energy compounds. ${ }^{42,43}$ Therefore, good stability is confirmed for title molecules.

\section{Detonation characters}

Detonation velocity (D) and detonation pressure (P) are two important parameters to decide the performance of the energetic materials. The Kamlet-Jacobs approach is used and the final data can be found in Table 4. The experimental detonation parameters of the benchmark explosives of RDX (hexahydro-1,3,5-trinitro-1,3,5triazine) and CL-20 (Hexanitrohexaazaisowurtzitane) are also listed.

Table 4. Detonation pressure and detonation velocity calculated at B3LYP/6$-311 \mathrm{G}^{* *}$ level accompanied with the Kamlet-Jacobs equation

\begin{tabular}{lcccc}
\hline Compound & $\rho\left(\mathrm{g} / \mathrm{cm}^{3}\right)$ & $Q(\mathrm{~J} / \mathrm{g})$ & $D(\mathrm{~km} / \mathrm{s})$ & $P(\mathrm{GPa})$ \\
\hline $1-$ & 1.54 & 2079.42 & 6.37 & 16.31 \\
$1,2-$ & 1.80 & 2074.80 & 8.16 & 29.51 \\
$1,4-$ & 1.81 & 2065.97 & 8.18 & 29.77 \\
$1,5-$ & 1.83 & 2055.69 & 8.23 & 30.36 \\
$1,2,3-$ & 2.00 & 2089.11 & 9.35 & 41.17 \\
$1,2,4-$ & 2.00 & 2070.42 & 9.32 & 40.98 \\
$1,2,6-$ & 2.04 & 2063.97 & 9.45 & 42.57 \\
$1,2,3,4-$ & 2.08 & 2078.32 & 9.93 & 47.47 \\
$1,2,4,5-$ & 2.14 & 2086.73 & 10.15 & 50.35 \\
$1,2,3,4,5-$ & 2.26 & 2103.16 & 10.81 & 58.84 \\
$1,2,3,4,5,6-$ & 2.32 & 2122.55 & 11.22 & 64.18 \\
RDX $^{\mathrm{a}}$ & 1.78 & 1591.03 & 8.87 & 34.67 \\
CL-20 $^{\mathrm{a}}$ & 1.98 & 1592.86 & 9.48 & 42.20 \\
\hline
\end{tabular}

${ }^{\mathrm{a}}$ Ref. 5 .

As is evident in Table 4, we found that there are strong linear relationships between $\rho$ and the substitution numbers $(n): \rho=0.1525 n+1.4758\left(R^{2}=0.9748\right), D=0.9365 n+6.0562$ $\left(R^{2}=0.9694\right)$, and $P=9.5305 n+9.9265\left(R^{2}=0.9904\right)$. The detonation performance increase as the introduction of associated groups. When 
the substituent number is more than three, the detonation performance is better than that of RDX and CL-20, which indicated their energetic characteristics and can be regarded as the candidate of high energy density compounds.

\section{CONCLUSIONS}

In this work, eleven derivatives of prismane are designed and investigated using the B3LYP/ 6-311G** method. The result shows all compounds have large heats of formation, and there is a good polynomial relationship between HOF and the substitution number. When more than three groups are introduced, the compounds have excellent detonation velocity and detonation pressure. Especially the hexadifluoroaminoprismane, its detonation velocity, and detonation pressure ever are over $11.0 \mathrm{~km} / \mathrm{s}$ and $60.0 \mathrm{GPa}$, respectively.

The thermal stability and pyrolysis mechanism of the title compounds are evaluated using the bond dissociation energies. The ring- $\mathrm{NF}_{2}$ bond is confirmed as the trigger bond in the detonation reaction. The bond dissociation energies of all prismane derivatives are larger than $200 \mathrm{~kJ} \mathrm{~mol}^{-1}$, which indicated that they have good thermodynamics stability. Also, all compounds have higher bandgaps than TATB, which implies that the prismane derivatives are with low impact sensitivity.

\section{SUPPLEMENTARY MATERIAL}

The cartesian coordinates of title molecules can be freely accessed at http://quimicanova.sbq.org.br, in PDF format.

\section{ACKNOWLEDGMENTS}

This project was supported by the Natural Science Foundation of Guizhou Province (Nos. QKHPTRC[2018]5778-09 and QKHJC[2020] 1Y038) and the Natural Science Foundation of Guizhou Education University (Nos. 14BS017 and 2019ZD001)

\section{REFERENCES}

1. Politzer, P.; Abrahmsen, L.; Sjoberg, P.; J. Am. Chem. Soc. 1984, 106, 855 .

2. Fried, L. E.; Ruggiero, A. J.; J. Phys. Chem. 1994, 98, 9786.

3. Stewart, J. P.; J. Mol. Model. 2004, 10, 155.

4. Benson, S. W.; Cruickshank, F. R.; Golden, D. M.; Haugen, G. R.; O’Neal, H. E.; Rodgers, A. S.; Shaw, R.; Walsh, R.; Chem. Rev. 1969, $69,279$.

5. Stewart, J. J. P.; J. Comput. Chem. 1989, 10, 221.

6. Li, B.; Li, L.; Yang, C.; Chin. J. Struct. Chem. 2020, 39, 643.

7. Zhang, J.-y.; Du, H.-c.; Wang, F.; Gong, X.-d.; Huang, Y.-s.; J. Phys. Chem. A 2011, 115, 6617.

8. Sikder, A. K.; Maddala, G.; Agrawal, J. P.; Singh, H.; J. Hazard. Mater. 2001, 84,1 .

9. Li, B.; Li, L.-L.; Liu, L.-L.; Mol. Phys. 2020, 118, e1708491.

10. Huynh, M. H. V.; Hiskey, M. A.; Chavez, D. E.; Naud, D. L.; Gilardi, R. D.; J. Am. Chem. Soc. 2005, 127, 12537.

11. Keshavarz, M. H.; J. Hazard. Mater. 2011, 190, 330.

12. Keshavarz, M. H.; Sadeghi, H.; J. Hazard. Mater. 2009, 171, 140.

13. Munday, L. B.; Chung, P. W.; Rice, B. M.; Solares, S. D.; J. Phys. Chem. B 2011, 115, 4378.
14. Podeszwa, R.; Rice, B. M.; Szalewicz, K.; Phys. Chem. Chem. Phys. 2009, 11, 5512

15. Nielsen, A. T.; Nissan, R. A.; Vanderah, D. J.; Coon, C. L.; Gilardi, R. D.; George, C. F.; Flippen-Anderson, J.; J. Org. Chem. 1990, 55, 1459.

16. Simpson, R. L.; Urtiew, P. A.; Ornellas, D. L.; Moody, G. L.; Scribner, K. J.; Hoffman, D. M.; Propellants, Explos., Pyrotech. 1997, 22, 249.

17. Zhang, M.-X.; Eaton, P. E.; Gilardi, R.; Angew. Chem., Int. Ed. 2000 , $39,401$.

18. Eaton, P. E.; Gilardi, R. L.; Zhang, M. X.; Adv. Mater. 2000, 12, 1143.

19. Kortus, J.; Pederson, M. R.; Richardson, S. L.; Chem. Phys. Lett. 2000, $322,224$.

20. Maier, G.; Neudert, J.; Wolf, O.; Pappusch, D.; Sekiguchi, A.; Tanaka, M.; Matsuo, T.; J. Am. Chem. Soc. 2002, 124, 13819.

21. Igor, N.; Chem. Phys. Lett. 2003, 380, 258.

22. Li, B.; Li, L.; Peng, J.; J. Mol. Model. 2020, 26, 253.

23. Li, B.; Li, L.; J. Mol. Model. 2020, 26, 114.

24. Dalinger, I. L.; Kormanov, A. V.; Suponitsky, K. Y.; Muravyev, N. V.; Sheremetev, A. B.; Chem. - Asian J. 2018, 13, 1165.

25. Google Patents, Archibald, T. G.; Manser, G. E., 1998.

26. Dalinger, I. L.; Shakhnes, A. K.; Monogarov, K. A.; Suponitsky, K. Y.; Sheremetev, A. B.; Mendeleev Commun. 2015, 25, 429.

27. Lee, C.; Yang, W.; Parr, R. G.; Phys. Rev. B 1988, 37, 785.

28. Frisch, M. J.; Trucks, G. W.; Schlegel, H. B.; Scuseria, G. E.; Robb, M. A.; Cheeseman, J. R.; Scalmani, G.; Barone, V.; Petersson, G. A.; Nakatsuji, H.; Li, X.; Caricato, M.; Marenich, A. V.; Bloino, J.; Janesko, B. G.; Gomperts, R.; Mennucci, B.; Hratchian, H. P.; Ortiz, J. V.; Izmaylov, A. F.; Sonnenberg, J. L.; Williams-Young, D.; Ding, F.; Lipparini, F.; Egidi, F.; Goings, J.; Peng, B.; Petrone, A.; Henderson, T.; Ranasinghe, D.; Zakrzewski, V. G.; Gao, J.; Rega, N.; Zheng, G.; Liang, W.; Hada, M.; Ehara, M.; Toyota, K.; Fukuda, R.; Hasegawa, J.; Ishida, M.; Nakajima, T.; Honda, Y.; Kitao, O.; Nakai, H.; Vreven, T.; Throssell, K.; Montgomery, J. A., Jr.; Peralta, J. E.; Ogliaro, F.; Bearpark, M. J.; Heyd, J. J.; Brothers, E. N.; Kudin, K. N.; Staroverov, V. N.; Keith, T. A.; Kobayashi, R.; Normand, J.; Raghavachari, K.; Rendell, A. P.; Burant, J. C.; Iyengar, S. S.; Tomasi, J.; Cossi, M.; Millam, J. M.; Klene, M.; Adamo, C.; Cammi, R.; Ochterski, J. W.; Martin, R. L.; Morokuma, K.; Farkas, O.; Foresman, J. B.; Fox, D. J.; Gaussian 03, Revision C.02., Gaussian Inc, Wallingford CT, 2004.

29. Ghule, V. D.; Jadhav, P. M.; Patil, R. S.; Radhakrishnan, S.; Soman, T.; J. Phys. Chem. A 2009, 114, 498.

30. Hehre, W. J.; Ditchfield, R.; Radom, L.; Pople, J. A.; J. Am. Chem. Soc. 1970, 92,4796

31. Fan, X.-W.; Ju, X.-H.; J. Comput. Chem. 2008, 29, 505.

32. Rice, B. M.; Pai, S. V.; Hare, J.; Combust. Flame 1999, 118, 445.

33. Harris, N. J.; Lammertsma, K.; J. Am. Chem. Soc. 1997, 119, 6583.

34. Blanksby, S. J.; Ellison, G. B.; Acc. Chem. Res. 2003, 36, 255.

35. Kamlet, M. J.; Jacobs, S. J.; J. Chem. Phys. 1968, 48, 23.

36. Kamlet, M. J.; Ablard, J.; J. Chem. Phys. 1968, 48, 36.

37. Kamlet, M. J.; Dickinson, C.; J. Chem. Phys. 1968, 48, 43.

38. Fukui, K.; Yonezawa, T.; Shingu, H.; J. Chem. Phys. 1952, 20, 722.

39. Kamlet, M. J.; Adolph, H. G.; Propellants, Explos., Pyrotech. 1979, 4, 30.

40. Mullay, J.; Propellants, Explos., Pyrotech. 1987, 12, 60.

41. McNesby, K. L.; Coffey, C. S.; J. Phys. Chem. B 1997, 101, 3097.

42. Liu, T.; Jia, J.; Li, B.; Gao, K.; Chin. J. Struct. Chem. 2019, 38, 688.

43. Brill, T. B.; James, K. J.; Chem. Rev. 1993, 93, 2667. 